\title{
Epidemiology of tuberculosis in big cities of the European Union and European Economic Area countries
}

G de Vries ${ }^{1,2}$, R W Aldridge3 ${ }^{3}$, A Caylà4, W. H. Haas ${ }^{5}$, A Sandgren ${ }^{6}$, N A van Hest7, I Abubakar (i.abubakar@ucl.ac.uk)

Tuberculosis in European Union Big Cities Working Group ${ }^{10}$

1. KNCV Tuberculosis Foundation, The Hague, the Netherlands

2. National Institute for Public Health and the Environment, Bilthoven, The Netherlands

3. University College London, Department of Infection and Population Health, London, United Kingdom

4. Public Health Agency of Barcelona, Barcelona, Spain

5. Robert Koch Institute, Berlin, Germany

6. European Centre for Disease Prevention and Control, Stockholm, Sweden

7. Municipal Public Health Service Rotterdam-Rijnmond, Rotterdam, the Netherlands

8. Public Health England, London, United Kingdom

9. University College London, London, United Kingdom

10. Working Group participants are listed at the end of the article

Citation style for this article:

de Vries G, Aldridge RW, Caylà JA, Haas WH, Sandgren A, van Hest NA, Abubakar I, the Tuberculosis in European Union Big Cities Working Group. Epidemiology of tuberculosis in big cities of the European Union and European Economic Area countries. Euro Surveill. 2014;19(9):pii=20726. Available online: http://www. eurosurveillance.org/ViewArticle.aspx?Articleld $=20726$

This cross-sectional survey aimed to examine the epidemiology of tuberculosis (TB) in European Union (EU) and European Economic Area (EEA) cities with populations greater than 500,000. National TB programme managers were asked to provide data on big city population size, total number of notified TB cases in big cities and national notification rate for 2009. A rate ratio was calculated using the big city TB notification rate as a numerator and country TB notification rate, excluding big city TB cases and population, as a denominator. Twenty of the 30 EU/EEA countries had at least one big city. Pooled rate ratios were $2.5,1.0$, and 0.7 in low-, intermediate- and high-incidence countries respectively. In 15 big cities, all in low-incidence countries, rate ratios were twice the national notification rate. These data illustrate the TB epidemiology transition, a situation whereby TB disease concentrates in big cities as national incidence falls, most likely as a result of the higher concentration of risk groups found there. This situation requires targeted interventions and we recommend that big city TB data, including information about patients' risk factors, are collected and analysed systematically, and that successful interventions are shared.

\section{Introduction}

Tuberculosis (TB) notification rates in the European Union (EU) have been declining at a mean annual rate of $4.4 \%$ since 2006 , and in 2010 there were 73,996 TB cases reported by the 27 EU Member States and the three European Economic Area (EEA) countries (Iceland, Liechtenstein and Norway) [1]. This resulted in notification rates below 100 per 100,000 population in all EU Member States for the first time in 2010. These national and EU-wide figures demonstrate the progress made towards the target of elimination, defined as less than one infectious (sputum smear-positive) case per 1,000,000 population [2]. However, they hide some of the wide variations that exist between and within countries.

Several publications have highlighted the higher notification and incidence rates in EU/EEA big cities or metropolitan areas, compared to non-urban areas, which is particularly evident among certain high-risk groups for TB overrepresented in big cities, including migrants from high-incidence countries, homeless people and drug and alcohol users [3-14]. The nomenclature used to describe major urban conurbations is variable within the literature, and includes big or large city, metropole or metropolitan area, urban area. The definition is often based on population size or density criteria. Cities are administrative areas (municipalities), while metropolitan areas usually combine urban agglomeration with peripheral zones that are not necessarily urban in character, but are closely bound to the centre by employment or commerce [15]. Urban and suburban areas can also share the general big city social structures underpinning the congregation of urban high-risk groups.

TB surveillance in Europe does not provide specific information on the epidemiology of TB in big cities, and data are only available routinely within countries and not readily accessible for international comparison. To inform the preparation of the consensus statement, which examined the structural determinants of TB in EU/EEA big cities, as well as provided 
recommendations for big city TB control [16], a survey of national TB programme managers was conducted. This cross-sectional survey aimed to provide detailed information of the epidemiology of TB in EU/EEA big cities, allowing an analysis of the case distribution and infection rates within low-, intermediate- and high-incidence EU/EEA countries and their big cities.

\section{Methods}

\section{Cross-sectional survey among national}

tuberculosis programme managers

For the purpose of this work we defined a big city as any municipality in the EU/EEA which had more than 500,000 inhabitants in 2009.

World Health Organization (WHO) national TB programme managers in EU/EEA countries were emailed by one of the authors ( $\mathrm{GdV}$ ) during the period from April 2011 to October 2012 using a list provided by the WHO Regional Office for Europe. TB programme managers received a form containing big city population size data, the total number of national notified TB cases, and national notification rate for their country in 2009. These pre-populated data were taken from various sources. City population estimates were taken from the Eurostat Population and living conditions in Urban Audit cities (core city) [17] or where not available other Internet sources such as Wikipedia were used. Country population sizes were taken from the Tuberculosis Surveillance in Europe 2009 report [18]. The total number of national notified TB cases in 2009 and the national notification rate were taken from the Tuberculosis Surveillance and monitoring in Europe 2012 report [1]. National TB programme managers were asked to verify (or change as necessary) this pre-populated data, or to send this information on to appropriate public health officials responsible for TB control in the big city under consideration. They were also asked to provide the number of TB cases for each big city identified within their country in 2009. Data received back from the national TB programme managers, or public health authorities responsible for TB control in these big cities, were collated in an Excel spreadsheet.

To examine the effect of big cities on TB incidence, we calculated rate ratios using the big city TB notification rate as a numerator and the country TB notification rate, excluding big city TB cases and population, as a denominator. National and big city TB notification rates and rate ratios were calculated in Stata (StataCorp LP, College Station, TX, USA) version 12.

Data were presented separately for low-, intermediate- and high-incidence EU/EEA countries and their big cities. Various definitions for low-incidence and high-incidence countries exist. The European Centre for Disease Prevention and Control (ECDC) defines countries with a TB incidence rate of $<20$ TB cases per 100,000 population as low-incidence countries entering the phase of elimination [1]. For this study we classified countries into low-incidence countries ( $\$ 20$ notifications per 100,000 population), mainly in western EU/EEA, and intermediate (20-50 notifications per $100,000)$ and high-incidence countries (>50 notifications per 100,000), mainly in the central and eastern EU.

Data from the tuberculosis control in European Union big cities working group

Annual notification rates for six selected big cities, available for the last 20 years, were collected in order to examine and exemplify time trends within these cities. Selection was based on participation in the working group, availability of data and its illustrative power to show a stable, declining or increasing trend. Two of these big cities with five-year inner city data available were selected to demonstrate the variation of TB notification rates within their big cities.

\section{Results}

Current epidemiology of tuberculosis in big cities - cross-sectional survey results

From the 30 EU/EEA countries, 20 had at least one big city (15/23 low-incidence, $3 / 5$ intermediate and $2 / 2$ high-incidence countries), with 54 big cities in total, 45 in low-incidence, seven in intermediate and two in high-incidence countries. All national TB programme managers or public health authorities from these big cities responded.

The population in big cities represented $12.4 \%$ of the total EU/EEA population. The highest notification rates in big cities in low-incidence countries were observed in Birmingham and London, United Kingdom (58.0, 44.4 respectively), followed by Brussels, Belgium (29.9), and Barcelona, Spain (27.0), all higher or considerably higher compared to their national TB notification rates (Table 1 ). The highest notification rates in big cities in intermediate and high-incidence countries were observed in Bucharest, Romania (87.1) and Riga, Latvia (43.0), followed by Sofia, Bulgaria (36.6) and Vilnius, Lithuania (31.9), all lower than their national TB notification rates.

The highest rate ratios (big city notification rate more than twice the national notification rate) were found in 15 big cities, all in low-incidence countries. Birmingham had the highest rate ratio followed by Brussels; London; and Rotterdam, the Netherlands (4.0, 3.2, 3.0 and 3.0 respectively); Copenhagen, Denmark; Milan, Italy; Oslo, Norway; Paris, France; and Turin, Italy (all 2.8); Amsterdam, the Netherlands (2.7); Rome, Italy (2.5); Frankfurt, Germany (2.4); Cologne, Germany (2.3); Athens, Greece (2.2); and Genoa, Italy (2.0).

Table 2 shows the aggregated population size, TB caseload and notification rates in EU/EEA countries and big cities according to notification rate at country level. In 2009, the TB notification rate across the EU/ EEA was 15.8 per 100,000 inhabitants and 22.3 in big 
TABLE 1

Population size, tuberculosis cases and notification rates in low-, intermediate- and high-incidence European Union/European Economic Area countries and their big cities (>500,000 population), and rate ratio for big cities, 2009 (20 countries, 54 cities)

\begin{tabular}{|c|c|c|c|c|c|c|c|c|}
\hline Country & Population & TB cases & $\begin{array}{c}\text { Notification } \\
\text { rate }\end{array}$ & Big city & Population & TB cases & $\begin{array}{l}\text { Notification } \\
\text { rate }\end{array}$ & Rate ratio ${ }^{\mathrm{a}}$ \\
\hline \multicolumn{9}{|c|}{ Low-incidence countries (TB incidence $<20$ per 100,000 population) } \\
\hline Austria & $8,355,260$ & 698 & 8.4 & Vienna & $1,698,957$ & 256 & 15.1 & 1.8 \\
\hline Belgium & $10,666,866$ & 994 & 9.3 & Brussels & $1,068,532$ & 320 & 29.9 & 3.2 \\
\hline Czech Republic & $10,467,542$ & 695 & 6.6 & Prague & $1,233,211$ & 128 & 10.4 & 1.6 \\
\hline Denmark & $5,511,451$ & 337 & 6.1 & Copenhagen & 667,228 & 113 & 16.9 & 2.8 \\
\hline Finland & $5,326,314$ & 417 & 7.8 & Helsinki & 583,350 & 58 & 9.9 & 1.3 \\
\hline \multirow{2}{*}{ France } & \multirow{2}{*}{$62,131,000^{b}$} & \multirow[b]{2}{*}{$5,114^{b}$} & \multirow{2}{*}{8.2} & Paris & $2,199,500$ & 515 & 23.4 & 2.8 \\
\hline & & & & Marseille & 852,396 & 103 & 12.1 & 1.5 \\
\hline \multirow{14}{*}{ Germany } & \multirow{14}{*}{$82,002,356$} & \multirow{14}{*}{4,419} & \multirow{14}{*}{5.4} & Berlin & $3,442,675$ & 269 & 7.8 & 1.4 \\
\hline & & & & Hamburg & $1,774,224$ & 178 & 10.0 & 1.9 \\
\hline & & & & Munich & $1,330,440$ & 103 & 7.7 & 1.4 \\
\hline & & & & Hannover & $1,130,262^{c}$ & 70 & 6.2 & 1.1 \\
\hline & & & & Cologne & 998,105 & 126 & 12.6 & 2.3 \\
\hline & & & & Frankfurt & 671,927 & 87 & 12.9 & 2.4 \\
\hline & & & & Bremen & 661,716 & 57 & 8.6 & 1.6 \\
\hline & & & & Stuttgart & 601,646 & 49 & 8.1 & 1.5 \\
\hline & & & & Dusseldorf & 586,217 & 57 & 9.7 & 1.8 \\
\hline & & & & Dortmund & 581,308 & 47 & 8.1 & 1.5 \\
\hline & & & & Essen & 572,569 & 21 & 3.7 & 0.7 \\
\hline & & & & Dresden & 518,862 & 30 & 5.8 & 1.1 \\
\hline & & & & Leipzig & 517,052 & 44 & 8.5 & 1.6 \\
\hline & & & & Nuremberg & 503,673 & 44 & 8.7 & 1.6 \\
\hline Greece & $11,260,402$ & 594 & 5.3 & Athens & 745,514 & 91 & 11.5 & 2.2 \\
\hline Hungary & $10,030,975$ & 1,407 & 14.0 & Budapest & $1,695,000$ & 321 & 18.9 & 1.4 \\
\hline \multirow{6}{*}{ Italy } & \multirow{6}{*}{$60,045,068$} & \multirow{6}{*}{4,244} & \multirow{6}{*}{7.1} & Rome & $2,724,347$ & 487 & 17.9 & 2.5 \\
\hline & & & & Milan & $1,650,000^{c}$ & 327 & 19.8 & 2.8 \\
\hline & & & & Naples & 963,661 & 68 & 7.1 & 1.0 \\
\hline & & & & Turin & 909,538 & 183 & 20.1 & 2.8 \\
\hline & & & & Palermo & 659,433 & 51 & 7.7 & 1.1 \\
\hline & & & & Genoa & 611,171 & 87 & 14.2 & 2.0 \\
\hline \multirow{2}{*}{ Netherlands } & \multirow{2}{*}{$16,485,787$} & \multirow{2}{*}{1,157} & & Amsterdam & 755,605 & 143 & 18.9 & 2.7 \\
\hline & & & 7.0 & Rotterdam & 699,609 & 128 & 21.3 & 3.0 \\
\hline Norway & $4,799,252$ & 358 & 7.5 & Oslo & 575,475 & 121 & 21,0 & 2.8 \\
\hline & & & & Madrid & $3,255,944$ & 580 & 17.8 & 1.1 \\
\hline & & & & Barcelona & $1,455,000$ & 393 & 27.0 & 1.6 \\
\hline Snain & & & & Valencia & 814,208 & 177 & 21.7 & 1.3 \\
\hline spain & $45,828,172$ & 7,592 & 16.6 & Seville & 703,206 & 107 & 15.2 & 0.9 \\
\hline & & & & Zaragoza & 674,317 & 117 & 17.4 & 1.0 \\
\hline & & & & Malaga & 568,305 & 93 & 16.4 & 1.0 \\
\hline Sweden & $9,256,347$ & 617 & 6.7 & Stockholm & 810,120 & 39 & 4.8 & 0.7 \\
\hline 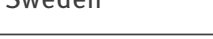 & $9,256,347$ & 617 & 0.7 & Gothenburg & 500,197 & 49 & 9.8 & 1.5 \\
\hline & & & & London & $7,753,555$ & 3,440 & 44.4 & 3.0 \\
\hline & & & & Glasgow & 878,135 & 213 & 24.3 & 1.7 \\
\hline United Kingdom & $61,179,256$ & 8,917 & 14.6 & Birmingham & 687,700 & 399 & 58.0 & 4.0 \\
\hline & & & & Leeds & 787,700 & 124 & 15.7 & 1.1 \\
\hline & & & & Sheffield & 547,000 & 80 & 14.6 & 1.0 \\
\hline Intermediate-inc & nce countries & B incidenc & -50 per 10 & o population) & & & & \\
\hline Bulgaria & $7,606,551$ & 2,910 & 38.3 & Sofia & $1,249,798$ & 457 & 36.6 & 1.0 \\
\hline Latvia & $2,261,294$ & 978 & 43.2 & Riga & 709,145 & 305 & 43.0 & 1.0 \\
\hline & & & & Warsaw & $1,711,466$ & 304 & 17.8 & 0.8 \\
\hline & & & & Krakow & 754,853 & 73 & 9.7 & 0.4 \\
\hline Poland & $38,135,876$ & 8,236 & 21.6 & Lodz & 744,541 & 187 & 25.1 & 1.2 \\
\hline & & & & Wroclaw & 632,240 & 175 & 27.7 & 1.3 \\
\hline & & & & Poznan & 556,022 & 70 & 12.6 & 0.6 \\
\hline High-incidence $\mathrm{C}$ & ntries (TB inci & ce $>50 \mathrm{pe}$ & 0,000 popu & & & & & \\
\hline Lithuania & $3,349,872$ & 2,081 & 62.1 & Vilnius & 558,165 & 178 & 31.9 & 0.5 \\
\hline Romania & $21,498,616$ & 23,164 & 107.7 & Bucharest & $1,944,226$ & 1,694 & 87.1 & 0.8 \\
\hline
\end{tabular}

TB: :tuberculosis.

a Rate ratio calculated using the big city TB notification rate as a numerator and country TB notification rate, excluding big city TB cases and population, as a denominator.

b Excluding overseas districts of France.

Populations of Hannover and Milan are for the greater municipal area/conglomerate.

Cities shown in blue are those with a rate ratio greater than or equal to 2.0. 
Aggregated population size, number of notified tuberculosis cases and notification rates stratified by tuberculosis notification rate and rate ratios of big city and country incidences, European Union/European Economic Area countries and their big cities, 2009 (30 countries, 45 cities)

\begin{tabular}{|c|c|c|c|c|c|c|c|c|c|}
\hline \multirow[b]{2}{*}{$\begin{array}{l}\text { Notification } \\
\text { (incidence rate) }\end{array}$} & \multicolumn{4}{|c|}{ EU/EEA countries } & \multicolumn{4}{|c|}{ EU/EEA big cities } & \multirow[b]{2}{*}{$\begin{array}{c}\text { Rate ratio } \\
(95 \% \mathrm{Cl})\end{array}$} \\
\hline & $\begin{array}{c}\text { Number } \\
\text { of } \\
\text { countries }\end{array}$ & Population & TB cases & $\begin{array}{l}\text { Notification } \\
\text { rate }^{a} \text { [range] }\end{array}$ & $\begin{array}{l}\text { Number of } \\
\text { big cities }\end{array}$ & Population & TB cases & $\begin{array}{l}\text { Notification } \\
\text { rate [range] }\end{array}$ & \\
\hline $\begin{array}{l}\text { Low }^{c} \\
\text { (o-20 cases) }\end{array}$ & 23 & $417,299,635$ & 38,868 & $\begin{array}{c}9.3 \\
{[5 \cdot 3-16.6]}\end{array}$ & 45 & $53,562,242$ & 10,493 & $\begin{array}{c}19.6 \\
{[3.7-58.0]}\end{array}$ & $\begin{array}{c}2.5 \\
{[2.5-2.6]}\end{array}$ \\
\hline $\begin{array}{l}\text { Intermediate } \\
(20-50 \text { cases })\end{array}$ & 5 & $59,971,386$ & 15,406 & $\begin{array}{c}25.7 \\
{[21.6-43.2]}\end{array}$ & 7 & $6,358,065$ & 1,571 & $\begin{array}{c}24 \cdot 7 \\
{[9.7-43.0]}\end{array}$ & $\begin{array}{c}1.0 \\
{[0.9-1.0]}\end{array}$ \\
\hline $\begin{array}{l}\text { High } \\
\text { (>50 cases) }\end{array}$ & 2 & $24,848,488$ & 25,245 & $\begin{array}{c}101.6 \\
{[62.1-108.2]}\end{array}$ & 2 & $2,502,391$ & 1,872 & $\begin{array}{c}74.8 \\
{[31.9-87.1]}\end{array}$ & $\begin{array}{c}0.7 \\
{[0.7-0.8]}\end{array}$ \\
\hline Total & 30 & $502,119,509$ & 79,519 & $\begin{array}{c}15.8 \\
{[5.3-108.2]}\end{array}$ & 54 & $62,422,698$ & 13,936 & $\begin{array}{c}22.3 \\
{[3.6-87.1]}\end{array}$ & $\begin{array}{c}1.5 \\
{\left[1.5^{-1.5}\right]}\end{array}$ \\
\hline
\end{tabular}

$\mathrm{Cl}$ : confidence interval; EU: European Union; EEA: European Economic Area; TB: tuberculosis

Low-incidence countries are defined as having $<20$ notifications per 100,000 population; intermediate-incidence countries as having $20-50$ notifications per 100,000 population; and and high-incidence countries countries as having $>50$ notifications per 100,000 population.

a Cases per 100,000 population per year.

b A rate ratio was calculated using the big city TB notification rate as a numerator and country TB notification rate as a denominator, after the exclusion of big cities population and TB cases from this national figure.

Excluding overseas districts of France.

cities, resulting in a rate ratio of 1.5 . Pooled rate ratios were $2.5,1.0$, and 0.7 in low-, intermediate- and highincidence countries respectively. Big cities of EU/EEA low-incidence countries accounted for $27.0 \%(10,493$ of 38,868 ) of the notified TB cases while only $12.8 \%$ of the general population lived in these cities.

\section{Tuberculosis control in big cities case studies}

Figure 1 presents examples of trends in TB notification rates over the past two decades in selected EU big cities. In the past two decades Barcelona and Paris notification rate has reduced from almost 70 per 100,000 population to around 25 while London has experienced almost a doubling of notification rates since 1990 from around 24 per 100,000 population to 45 . Brussels continues to have high notification rates between 30 and 40 per 100,000 population, while Berlin, Germany, maintains a low notification rate of around 10 , although an increase was observed in the past two years. In Rotterdam, the TB notification rate initially almost doubled from 1990 and reached 29 per 100,000 in 2003 but then the increasing trend reversed to a rate of 15 per 100,000 in 2011.

Notification rates also vary within different districts of a city. In London and in Rotterdam, levels were highest in the inner city districts (Figure 2). However, this is not consistent across all EU big cities; for example in Stockholm, Sweden, socially disadvantaged groups tend to live outside the city, in suburbs with higher notification rates than for the city itself (personal communication, J Jonsson, December 2011).

\section{Discussion}

This study presents the results of a cross-sectional survey of national and big city TB programme managers, examining the distribution of TB cases and rates within EU/EEA countries and big cities. In 2009, 15 out of 54 EU/EEA big cities had a notification rate two times greater than the national notification rate and all were in low-incidence countries. The TB notification rate across the EU/EEA was 15.8 per 100,000 population (excluding overseas districts of France) compared to 22.3 in the big cities. In low-incidence EU/EEA countries, $\mathbf{2 7 . 0} \%$ of TB cases lived in big cities, compared to only $12.8 \%$ of the general population residing there. These data illustrate the high levels of TB found in EU/EEA big cities that are not obvious when examining national data alone. Analysis of available longterm data for EU/EEA big cities show that while there is a general downward trend, some big cities such as London have seen an increase in notifications over recent years.

In the United States (US) a study examined all incident cases of TB reported to the Centers for Disease Control and Prevention's National Tuberculosis Surveillance System (NTSS) from 2000 to 2007 [19]. This study found that a significant TB burden occurs in large US cities with $36 \%$ of all US TB patients living in 48 cities compared with only $15 \%$ of the general US population. TB incidence rates in these cities $(12.1 / 100,000)$ were four times higher than that in the US when excluding the cities $(3.8 / 100,000)$. 
Trends of tuberculosis notification rates in selected big cities in low-incidence European Union/European Economic Area countries, 1990-2011

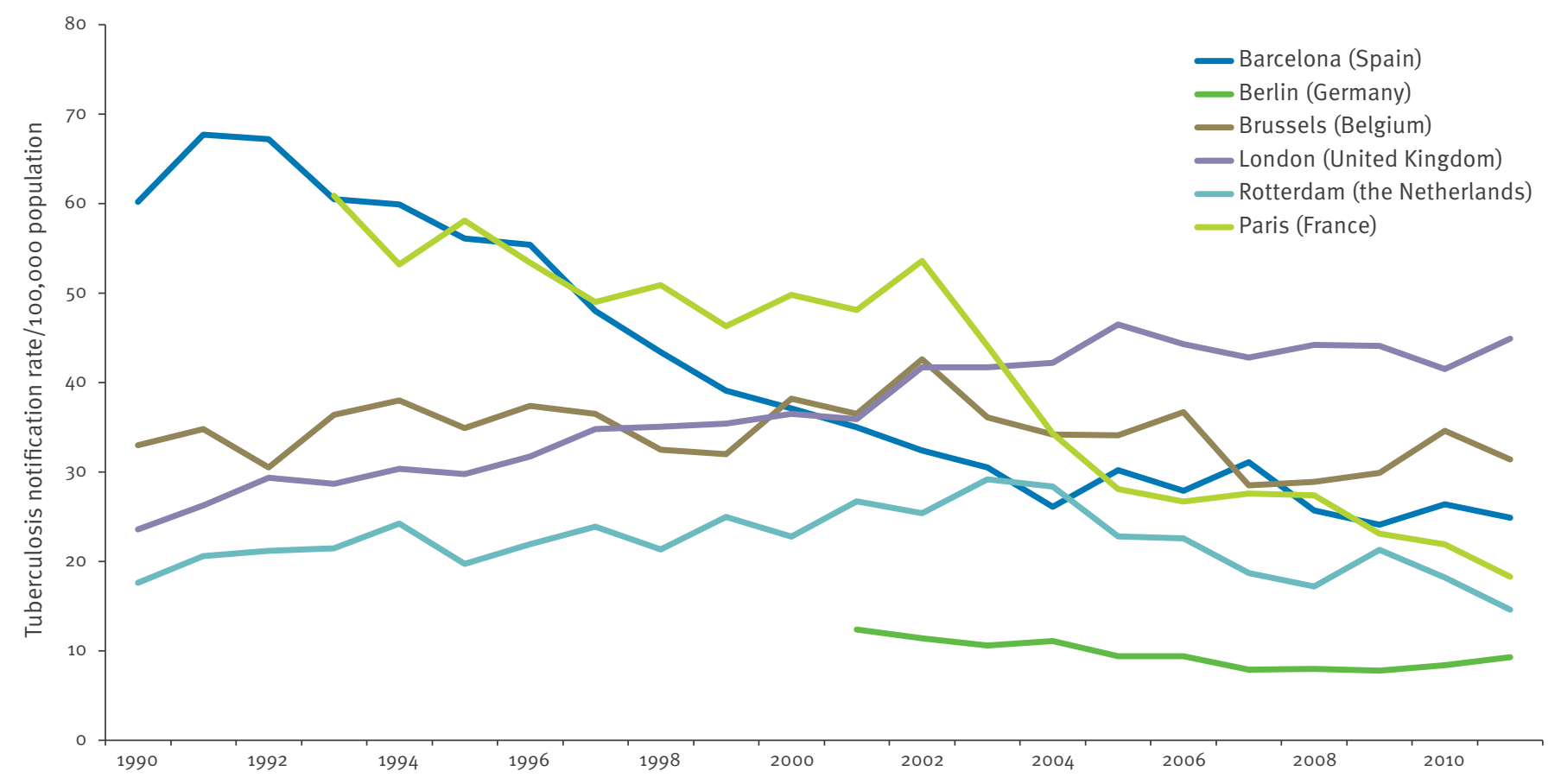

Selection was based on participation in the European Union big cities working group, availability of data and its illustrative power to show a stable, declining or increasing trend. Paris data available from 1993, Berlin data available from 2001.

A European study conducted in 1999-2000 contacted national TB coordinators in western European countries (or their public health counterparts in the appropriate cities) and asked them to provide TB epidemiological data [5]. Notification rates in cities were found to range from less than 10 per 100,000 population to 70 . Notification rates were more than double the overall rate for the country in eight of the cities (Brussels; Copenhagen; Paris; Thessaloniki, Greece; Milan; Amsterdam; The Hague, the Netherlands; and London). These findings were consistent with those of our study which also found Brussels, Copenhagen, Paris, Milan, Amsterdam, and London to have a rate ratio of greater than two (Thessaloniki and The Hague did not meet our criteria for big city). In addition to the disparities that exist between levels within countries and their big cities, there is also variation within big cities themselves within different districts of a city.

Our study used a narrow definition of TB in big cities to refer to cases residing within the administrative boundaries of a municipality, although for two big cities (Hannover, Germany; and Milan) information was not available. TB case ascertainment is a dynamic process both in EU/EEA countries and in their big cities, so the actual number of cases and notification rate may change over time. Since we collected the data on TB in big cities at approximately the same time as EU/
EEA countries uploaded the revised 2009 data to ECDC, presented in the 2012 report [1], we optimised comparison of data. Our study did not collect data on risk factors of urban and national TB cases, which may further explain the urban-rural difference found in this study. We also did not gather information on TB control strategies and resources, which may differ in urban and rural areas, and effect case detection and notification levels.

Factors contributing to the high notification rates in western EU/EEA big cities are likely to be related to the relatively high proportion of immigrants from high-incidence countries, outbreaks among homeless people, drug users and alcoholics, and on-going transmission to other urban populations $[5,10,19,20]$. Factors such as the high population density in big cities, the high prevalence of congregate settings, population pockets in big cities with lower socio-economic status [21], and at times inadequate public health responses [22-24], are also likely to contribute to higher TB notification rates in big cities.

Our study shows that with TB notification rates declining to less than 20 per 100,000 population, in most EU/ EEA countries, TB rates in big cities remain higher than the national notification rate. Our data also illustrate the TB epidemiology transition: a situation whereby TB 


\section{FIGURE 2}

Average tuberculosis notification rates per 100,000 population and by borough or postal code area in London and Rotterdam, 2007-2011
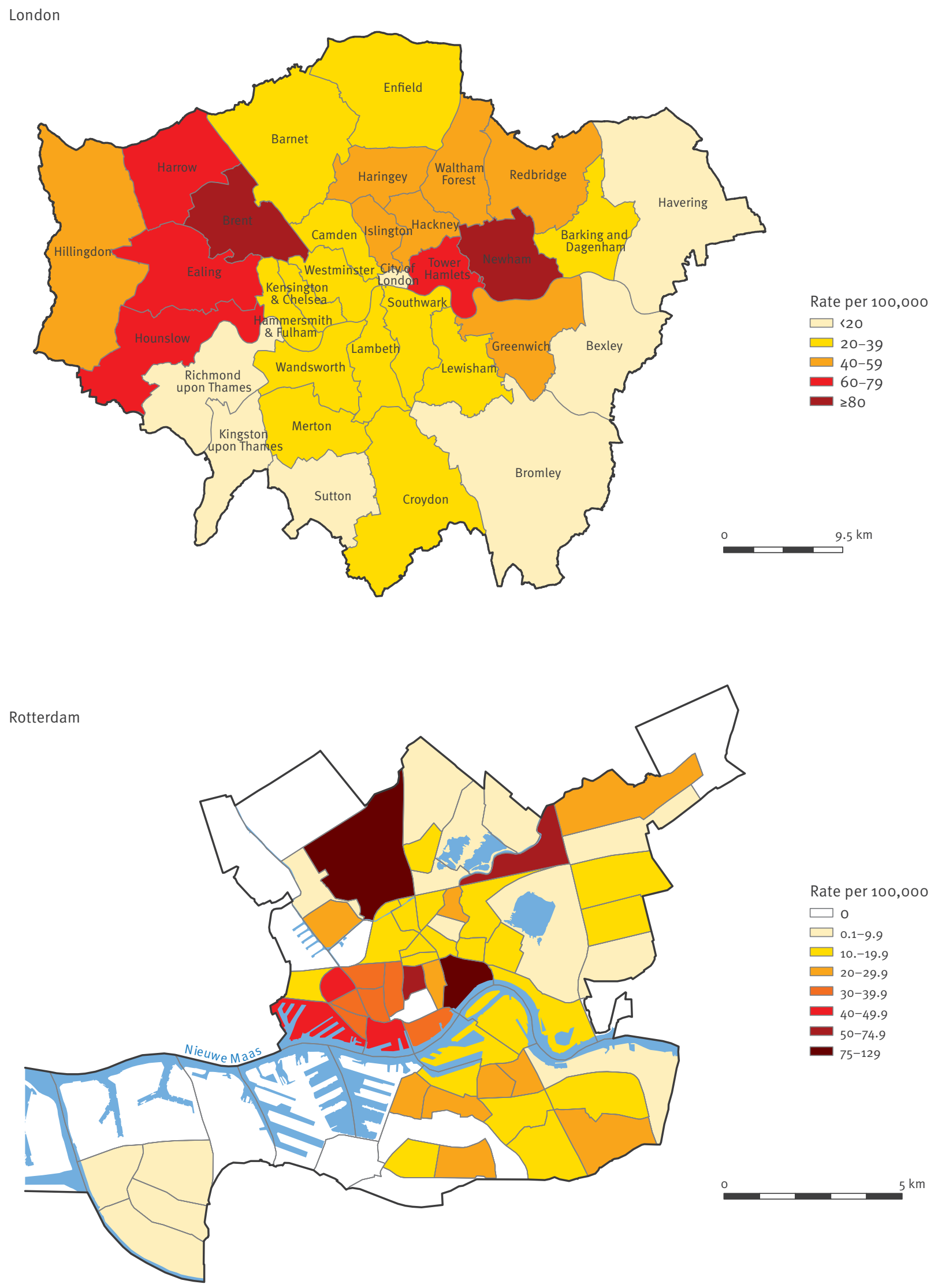
disease concentrates in big cities as national incidence falls, most likely as a result of the risk groups found there. We expect that countries going down from high and intermediate incidence to low-incidence are likely to experience the same phenomenon and should consider this changing epidemiological situation in their TB control programmes in a timely manner. To tackle this problem we recommend that big city TB data, including risk profiles of patients, are collected and analysed systematically and that interventions to control TB successfully in big cities are shared. The accompanying consensus statement on TB goes some way to ensuring consistency in approaches that are required [16].

Members of Tuberculosis in European Union Big Cities Working Group

D. Antoine: Institut de Veille Sanitaire, Paris, France. F. Antoun: Direction de l'Action Sociale de l'Enfance et de la Santé, Paris, France. W. Arrazola de Oñate: Belgian Lung and Tuberculosis Association, Brussels, Belgium. L.R. Codecasa: Villa Marelli Regional TB Reference Centre, Niguarda Hospital, Milan, Italy. M. Dedicoat: Heart of England Hospital Chest Department, Birmingham, United Kingdom. H. van Deutekom: Municipal Public Health Service Amsterdam, Amsterdam, The Netherland s. A. Gori: TB PANNET, San Gerardo Hospital, University of Milan, Italy. B. Hauer: Robert Koch Institute, Berlin, Germany. A. Hayward: UCL Department of Infection /Population Health, London, United Kingdom. E. Huitric: European Centre for Disease Prevention and Control, Stockholm, Sweden. J. Jonsson: Swedish Institute for Infectious Disease Control, Stockholm, Sweden. À. Orcau: Public Health Agency of Barcelona, Barcelona, Spain. L. Quabeck: Senatsverwaltung für Gesundheit, Umwelt und Verbraucherschutz, Berlin, Germany. Berlin. A. Rodés: Catalan Health Department, Barcelona, Spain. A. Story: Find \& Treat, London, United Kingdom. M. Wanlin: Belgian Lung and Tuberculosis Association, Brussels, Belgium. P. Williams: The Archive Institute, London, United Kingdom. Apart from working group members, data were provided by: P.H.S. Andersen, Denmark; B. Bonita, Berlin, Germany. N. Cioran, Romania; J.C. Cameron, Scotland; E. Davidaviciene, Lithuania; R. Kalkouni, Greece; Korányi Bulletin, Hungary; M. Korzeniewska, Poland. V. Martini, Italy; V. Milanov, Bulgaria; V. Riekstina, Latvia; Elena Rodríguez Valín, Spain; K. Rønning, Norway; B. Schmidgruber, Austria; T. Vasankari, Finland; J. Wallenfels, Czech Republic.

\section{Acknowledgments}

Maps for Figure 2 were produced by C. Andersen and S. Kanagarajah, Public Health England, London, United Kingdom; B. Bom, National Institute for Public Health and the Environment, Bilthoven, The Netherlands.
Authors' contributions

GdV wrote the first draft of the manuscript. All authors contributed to the editing of the paper and have seen and agreed the final version.

\section{Conflict of interest}

None declared.

\section{References}

1. European Centre for Disease Prevention and Control, World Health Organization. Regional Office for Europe. Tuberculosis surveillance and monitoring in Europe 2012. Stockholm: European Centre for Disease Prevention and Control; 2012.

2. Broekmans JF, Migliori GB, Rieder HL, Lees J, Ruutu P, Loddenkemper R, et al. European framework for tuberculosis control and elimination in countries with a low incidence. Recommendations of the World Health Organization (WHO), International Union Against Tuberculosis and Lung Disease (IUATLD) and Royal Netherlands Tuberculosis Association (KNCV) Working Group. Eur Respir J. 2002 Apr;19(4):765-75. http://dx.doi.org/10.1183/09031936.02.00261402

3. Rodrigo T, Caylà JA, Galdós-Tangüis H, García de Olalla P, Brugal MT, Jansà JM. Proposing indicators for evaluation of tuberculosis control programmes in large cities based on the experience of Barcelona. Int J Tuberc Lung Dis. 2001 May;5(5):432-40.

4. Diel R, Schneider S, Meywald-Walter K, Ruf C, Rusch-Gerdes $\mathrm{S}$, Niemann S. Epidemiology of tuberculosis in Hamburg, Germany: long-term population-based analysis applying classical and molecular epidemiological techniques. Journal of Clinical Microbiology. 2002 Feb;40(2):532-9. http://dx.doi.org/10.1128/JCM.40.2.532-539.2002

5. Hayward AC, Darton T, Van-Tam JN, Watson JM, Coker R, Schwoebel V. Epidemiology and control of tuberculosis in Western European cities. Int J Tuberc Lung Dis. 2003 Aug;7(8):751-7.

6. Lukács J, Tubak V, Mester J, Dávid S, Bártfai Z, Kubica T, et al. Conventional and molecular epidemiology of tuberculosis in homeless patients in Budapest, Hungary. J Clin Microbiol. 2004;42(12):5931-4

http://dx.doi.org/10.1128/JCM.42.12.5931-5934.2004

7. Falzon D, Ait-Belghiti F. What is tuberculosis surveillance in the European Union telling us? Clinical Infectious Diseases. 15 May 2007;44(10):1261-7. http://dx.doi.org/10.1086/514343

8. Farge D, Porcher R, Antoun F, Fain O, Keshtmand H, Rocher $\mathrm{G}$, et al. Tuberculosis in European cities: establishment of a patient monitoring system over 10 years in Paris, France. Int J Tuberc Lung Dis. 2007;11(9):992-8.

9. De Vries G, van Hest RA, Richardus JH. Impact of Mobile Radiographic Screening on Tuberculosis among Drug Users and Homeless Persons. Am J Respir Crit Care Med. 2007;176:201-7. http://dx.doi.org/10.1164/rccm.200612-18770C

10. De Vries G, van Hest NAH, Baars HWM, Sebek MMGG, Richardus JH. Factors associated with the high tuberculosis case rate in an urban area. Int J Tuberc Lung Dis. 2010 Jul;14(7):859-65.

11. Bothamley GH, Kruijshaar ME, Kunst $H$, Woltmann G, Cotton $M$, Saralaya D, et al. Tuberculosis in UK cities: workload and effectiveness of tuberculosis control programmes. BMC Public Health. 2011;11(1):896. http://dx.doi.org/10.1186/1471-2458-11-896

12. Jit M, Stagg HR, Aldridge RW, White PJ, Abubakar I, For the Find and Treat Evaluation Team. Dedicated outreach service for hard to reach patients with tuberculosis in London: observational study and economic evaluation. BM). 2011 Sep;343(sep13 5):d5376-d5376.

13. Maguire H, Brailsford S, Carless J, Yates M, Altass L, Yates S, et al. Large outbreak of isoniazid-monoresistant tuberculosis in London, 1995 to 2006: case-control study and recommendations. Euro Surveill. 31 Mar 2011;16(13). pii $=19830$.

14. Goetsch U, Bellinger OK, Buettel K-L, Gottschalk R. Tuberculosis among drug users and homeless persons: impact of voluntary X-ray investigation on active case finding. Infection. 2012;40(4):389-95.

http://dx.doi.org/10.1007/S15010-011-0238-x 
15. Wikimedia Foundation, Inc. Wikipedia. Metropolitan area. [Accessed 23 Jul 2013]. Available from: https://en.wikipedia. org $/$ w/index.php?title=Metropolitan_area\&oldid $=565317267$

16. van Hest NA, Aldridge RW, de Vries G, Sandgren A, Hauer B, Hayward A, Arrazola de Oñate W, Haas W, Codecasa LR, Caylà JA, Story A, Antoine D, Gori A, Quabeck L, Jonsson J, Wanlin M, Orcau Â, Rodes A, Dedicoat M, Antoun F, van Deutekom $\mathrm{H}$, Keizer ST, Abubakar I. Tuberculosis control in big cities and urban risk groups in the European Union: a consensus statement . Euro Surveill. 2014;19(9):pii=20728.

17. Eurostat [web site] (2013). Luxembourg, European Commission. Available from: http://epp.eurostat.ec.europa.eu/portal/page/ portal/eurostat/home/

18. European Centre for Disease Prevention and Control, World Health Organization. Regional Office for Europe. Tuberculosis surveillance in Europe, 2009. Stockholm, Sweden; Copenhagen, Denmark: European Centre for Disease Prevention and Control; WHO Regional Office for Europe; 2011.

19. Oren E, Winston C, Pratt R, Robison V, Narita M. Epidemiology of urban tuberculosis in the United States, 2000-2007. Am J Public Health. 2011 Jul;101(7):1256-63. http://dx.doi.org/10.2105/AJPH.2010.300030

20. Story A, Murad S, Roberts W, Verheyen M, Hayward AC. Tuberculosis in London: the importance of homelessness, problem drug use and prison. Thorax. 2007;62(8):667-671. http://dx.doi.org/10.1136/thx.2006.065409

21. Mangtani P, Jolley DJ, Watson JM, Rodrigues LC. Socioeconomic deprivation and notification rates for tuberculosis in London during 1982-91. BMJ. 15 Apr 1995;310(6985):963-6. http://dx.doi.org/10.1136/bmj.310.6985.963

22. Frieden TR, Fujiwara PI, Washko RM, Hamburg MA. Tuberculosis in New York City-turning the tide. N Engl J Med. 1995;333:229-33. http://dx.doi.org/10.1056/NEJM199507273330406

23. De Vries G, van Hest RA. From contact investigation to tuberculosis screening of drug addicts and homeless persons in Rotterdam. Eur J Public Health. 2006;16:133-6. http://dx.doi.org/10.1093/eurpub/cki203

24. Hayward J, Murray D, Iny I, Jarrett J, Lonergan K, Pillas D, et al (Public Health Action Support Team (PHAST)). London TB Service Review and Health Needs Assessment. London: PHAST; 2010. [Accessed March 2014]. Available from: https:// www.brit-thoracic.org.uk/Portals/o/Clinical\%2olnformation/ Tuberculosis/P263\%20PHAST\%20London\%20TB\%20 Project\%20Final\%2oreport\%20l.pdf 